\title{
Formation of a Cobalt(III) Imido from a Cobalt(II) Amido Complex. Evidence for Proton-Coupled Electron Transfer
}

\author{
Ryan E. Cowley ${ }^{\dagger}$, Ranko P. Bontchev ${ }^{\ddagger}$, John Sorrell ${ }^{\dagger}$, Orcino Sarracino ${ }^{\dagger}$, Yanhua Feng ${ }^{\dagger}$, \\ Haobin Wang ${ }^{\dagger}$, and Jeremy M. Smith ${ }^{\dagger}$ \\ $\dagger$ Department of Chemistry and Biochemistry, New Mexico State University, Las Cruces NM 88003 USA \\ $\$$ Sandia National Laboratories, P.O. Box 5800, M.S. 0779, Albuquerque NM 87185 USA
}

\begin{abstract}
A key step in the oxidation of water to $\mathrm{O}_{2}$ in the catalytic cycle of Photosystem II is the conversion of a $\mathrm{MnOH}$ species to $\mathrm{MnO}$. This transformation is proposed to occur through proton-coupled electron transfer (PCET) ${ }^{1}$ from the hydroxo ligand to a nearby tyrosyl radical. ${ }^{2}$ Examples of this transformation in well-characterized systems are rare. ${ }^{3}$ The reverse reaction, in which a hydrogen atom is abstracted from a substrate by a highly reactive metal oxo intermediate, is more commonly observed. ${ }^{4}$ Imido ligands, which are often considered to be surrogates for oxos, display similar reactivity. Thus, hydrogen abstraction by imidos is often observed, 5,6 but their formation by PCET from an amido complex has not been reported. ${ }^{7}$

Here we describe the formation of a cobalt(III) imido complex from the corresponding cobalt (II) amido complex, and present computational data consistent with a concerted (PCET) pathway.
\end{abstract}

The four-coordinate complex $\mathrm{LCoCl}^{8}$ ( $\mathrm{L}=$ phenyltris(1-tertbutylimidazol-2-ylidene)borato) reacts with $\mathrm{LiNH}^{\mathrm{t}} \mathrm{Bu}$ to form the dark green, high spin $(S=3 / 2)$ amido complex $\mathrm{LCoNH}^{\mathrm{t}} \mathrm{Bu}$ in high yield. This rare example of a monomeric cobalt amido complex has been crystallographically characterized (Fig. 1a). The asymmetric unit consists of three crystallographically independent molecules, all showing identical structural features. The Co$\mathrm{N}$ bond lengths (1.886(7)-1.88(2) $\AA$ ) and bent Co-N-C linkages (152.5(2)-172.4(9) $)^{\circ}$ ) are comparable to those of other three- and four-coordinate cobalt amido complexes. ${ }^{9}$

The ${ }^{1} \mathrm{H}$ NMR spectrum of the complex is consistent with the X-ray crystal structure. Seven paramagnetically shifted resonances are observed and can be assigned on the basis of integration. A weak band at $3149 \mathrm{~cm}^{-1}$ in the IR spectrum is assigned to the $\mathrm{N}-\mathrm{H}$ stretching vibration. Although sensitive to both water and oxygen, this complex has significantly greater thermal stability than most late transition metal alkylamido complexes, remaining unchanged for days at $100{ }^{\circ} \mathrm{C}$.

Reaction of the amido complex with the stable 2,4,6-tri(tert-butyl)phenoxy radical ${ }^{10}$ results in immediate formation of the lilac cobalt(III) imido complex $\mathrm{LCoN}^{\mathrm{t}} \mathrm{Bu}$ in high yield (Scheme 1). The diamagnetic cobalt product has been characterized by X-ray crystallography (Fig. 1b) and ${ }^{1} \mathrm{H}$ NMR spectroscopy, and the 2,4,6-tri(tert-butyl)phenol byproduct has been characterized by ${ }^{1} \mathrm{H}$ NMR spectroscopy. The X-ray crystal structure of $\mathrm{LCoN}{ }^{t} \mathrm{Bu}$ shows similar features to related complexes. In particular, the short $\mathrm{Co}(1)-\mathrm{N}(41)$ bond length (1.660(3) $\AA$ ) and linear $\mathrm{Co}(1)-\mathrm{N}(41)-\mathrm{C}(41)$ bond angle $\left(179.7(3)^{\circ}\right)$ are in line with other structurally characterized cobalt(III) imidos. ${ }^{11}$ This transformation is unique in the synthesis of late metal imido complexes, which are typically prepared via nitrene capture by low valent precursors. 
At least three mechanisms for the formation of $\mathrm{LCo}^{\mathrm{III}} \mathrm{N}^{t} \mathrm{Bu}$ can be proposed (Scheme 2, the corresponding organic species are not shown). ${ }^{12}$ The cobalt(II) amido complex could react by electron transfer (ET) to form an intermediate cationic cobalt(III) amido complex,

$\mathrm{LCoNH}^{t} \mathrm{Bu}^{+}$, followed by proton transfer (PT) to form the imido product, a pathway analogous to the route followed in the synthesis of $(\mathrm{dtbpe}) \mathrm{Ni}=\mathrm{N}\left(2,6-{ }^{\mathrm{i}} \mathrm{Pr}_{2} \mathrm{C}_{6} \mathrm{H}_{3}\right) \cdot{ }^{13} \mathrm{~A}$ second possibility is that the cobalt(III) imido product is formed by successive PT and ET steps via an anionic cobalt(II) imido intermediate $\mathrm{LCoN}^{t} \mathrm{Bu}^{-}$. Alternatively, the reaction could occur in a concerted PCET step that avoids formation of any of the intermediates.

We have calculated the relative free energies for all species in the thermodynamic cycle using density functional theory with hybrid functional (B3LYP/6-31G*). In the cases where the spinstates of the proposed intermediate cobalt complexes are not known, the energies of all possible spin states were calculated. ${ }^{14}$ The lowest energy spin state was used to determine relative free energy barriers (Scheme 2, relative energies in $\mathrm{kcal} / \mathrm{mol}$ ). Diethyl ether solvent was included using the polarizable continuum model (PCM). The free energy barriers obtained using the smaller SDD basis set are comparable (within $5 \mathrm{kcal} / \mathrm{mol}$ ) to those obtained with the $6-31 \mathrm{G}^{*}$ basis set.

The computational results are consistent with a concerted mechanism. The pathway for PCET is lower than for the alternative stepwise mechanisms that involve initial electron or proton transfer. We have also found that the free energy differences are similar to the electronic energy differences, and thus entropic contributions will not alter our conclusion.

Our experimental observations are consistent with the calculations. Thus, we have been unable to access the high energy complex $\mathrm{LCoN}^{t} \mathrm{Bu}^{-}$by deprotonation of $\mathrm{LCoNH} \mathrm{H}^{\mathrm{B}} \mathrm{Bu}$. No reaction is observed with LDA, while in the case of $\mathrm{MeLi}$, metathesis occurs to yield the previously characterized complex LCoMe. ${ }^{8}$ Furthermore, no reduction wave was observed in the cyclic voltammogram of $\mathrm{LCoN}^{\mathrm{t}} \mathrm{Bu}$. Likewise, initial electron transfer from $\mathrm{LCoNH} \mathrm{H}^{\mathrm{B}} \mathrm{Bu}$ to the 2,4,6tri(tert-butyl)phenoxy radical was found to be thermodynamically uphill.

The relative free energies calculated for $\mathrm{LCoNH}^{t} \mathrm{Bu}$ and $\mathrm{LCoN}^{t} \mathrm{Bu}$ have also allowed us to estimate the gas phase N-H BDE (enthalpy) of LCoNH ${ }^{t} \mathrm{Bu}$ to be $75 \mathrm{kcal} / \mathrm{mol}$. This is consistent with the spontaneous reaction observed with the 2,4,6-tri(tert-butyl)phenoxy radical (O-H $\mathrm{BDE}$ of 2,4,6-tri(tert-butyl)phenol is $81.2 \mathrm{kcal} / \mathrm{mol}) .{ }^{15}$ However, we have been unable to experimentally determine a lower limit for the $\mathrm{N}-\mathrm{H}$ BDE. Even substrates with weak bonds (e.g. TEMPO-H, O-H BDE $=69.7 \mathrm{kcal} / \mathrm{mol}),{ }^{16}$ do not react with $\mathrm{LCON}{ }^{t} \mathrm{Bu}$. This may be due to a kinetic barrier resulting from the bulkiness of the ligands, and it is thus notable that TEMPO does not react with $\mathrm{LCoNH}{ }^{\mathrm{t}} \mathrm{Bu}$.

In summary, we have found that a cobalt(III) imido can be prepared from the corresponding cobalt(II) amido complex. A computational investigation of the relative free energies for stepwise and concerted mechanisms is consistent with the concerted pathway involving PCET. Further studies are underway to kinetically investigate the mechanism of this transformation and extend this approach to other metals and metal-ligand multiple bonds.

\section{Supplementary Material}

Refer to Web version on PubMed Central for supplementary material.

\section{ACKNOWLEDGMENTS}

This research was supported by the ACS-PRF, NMSU and NSF CAREER (CHE 0348956 to HW), OS acknowledges summer support from NIH-BRIDGES (R25 GM048998). The Bruker X8 X-ray diffractometer was purchased via an 
NSF CRIF:MU award to the University of New Mexico, CHE-0443580. We thank Eileen Duesler for the X-ray data collection and Cindy Zoski for assistance with CV measurements.

\section{References}

1. PCET is defined as the concerted transfer of an electron and a proton. See:Mayer JM. Annu. Rev. Phys. Chem 2004;55:363. [PubMed: 15117257]

2(a). Recent reviews:Carrell TG, Tyryshkin AM, Dismukes GC. J. Biol. Inorg. Chem 2002;7:2. [PubMed: 11862536] (b) Mukhopadhyay S, Mandal SK, Bhaduri S, Armstrong WH. Chem. Rev 2004;104:3981. [PubMed: 15352784](c)VrettosJSBrudvigGWMcClevertyJAMeyerTJOxygen Evolution. Comprehensive Coordination Chemistry II2004507547ElsevierOxford (d) Messinger J. Phys. Chem. Chem. Phys 2004;6:4764.

3(a). Conproportionation of aqua and oxo ligands by PCET: Binstead RA, Stultz LK, Meyer TJ. Inorg. Chem 1995;34:546. (b) Nemes A, Bakac A. Inorg. Chem 2001;40:2720. [PubMed: 11375686] (c) Jensen KB, McKenzie CJ, Pedersen JZ. Inorg. Chem 2001;40:5066. [PubMed: 11559059]

4(a). For example, in terminal iron oxo complexes: Shan X, Que L. J. Inorg. Biochem 2006;100:421. [PubMed: 16530841] (b) MacBeth CE, Golombek AP, Young VG, Yang C, Kuczera K, Hendrich MP, Borovik AS. Science 2000;289:938. [PubMed: 10937994] (c) MacBeth CE, Gupta R, MitchellKoch KR, Young VG, Lushington GH, Thompson WH, Hendrich MP, Borovik AS. J. Am. Chem. Soc 2004;126:2556. [PubMed: 14982465] (d) Pestovsky O, Bakac A. J. Am. Chem. Soc 2004;126:13757. [PubMed: 15493935] (e) Kaizer J, Klinker EJ, Oh NY, Rohde J-U, Song WJ, Stubna A, Kim J, Münck E, Nam W, Que L. J. Am. Chem. Soc 2004;126:472. [PubMed: 14719937] (f) Oh NY, Suh Y, Park MJ, Seo MS, Kim J, Nam W. Angew. Chem. Int. Ed 2005;44:4235.

5(a). Jensen MP, Mehn MP, Que L. Angew. Chem. Int. Ed 2003;42:4357. (b) Kogut E, Wiencko HL, Zhang L, Cordeau DE, Warren TH. J. Am. Chem. Soc 2005;127:11248. [PubMed: 16089446] (c) Lucas RL, Powell DR, Borovik AS. J. Am. Chem. Soc 2005;127:11596. [PubMed: 16104724] (d) Eckert NA, Vaddadi S, Stoian S, Lachicotte RJ, Cundari TR, Holland PL. Angew. Chem. Int. Ed 2006;45:6868.

6(a). Thyagarajan S, Shay DT, Incarvito CD, Rheingold AL, Theopold KH. J. Am. Chem. Soc 2003;125:4440. [PubMed: 12683812] (b) Shay DT, Yap GPA, Zakharov LN, Rheingold AL, Theopold KH. Angew. Chem. Int. Ed 2005;44:1508.

7(a). Formation of $\left[\mathrm{Os}^{\mathrm{V}}\right]=\mathrm{N}-\mathrm{NR}_{2}$ from [Os $\left.{ }^{\mathrm{IV}}\right]-\mathrm{NH}-\mathrm{NR}_{2}$ by PCET: Huynh MHV, Meyer TJ, White PS. J. Am. Chem. Soc 1999;121:4530. (b) Huynh MHV, Meyer TJ. Proc. Nat. Acad. Sci 2004;101:13138. [PubMed: 15331783]

8. Cowley RE, Bontchev RP, Duesler EN, Smith JM. Inorg. Chem 2006;45:9771. [PubMed: 17112274]

9(a). Murray BD, Power PP. Inorg. Chem 1984;23:4584. (b) Putzer MA, Neumüller B, Dehnicke K, Magull J. Chem. Ber 1996;129:715. (c) Panda A, Stender M, Wright RJ, Olmstead MM, Klavins P, Power PP. Inorg. Chem 2002;41:3909. [PubMed: 12132915] (d) Panda A, Stender M, Olmstead MM, Klavins P, Power PP. Polyhedron 2003;22:67.

10. Altwicker ER. Chem. Rev 1967;67:475.

11(a). Other cobalt(III) imidos:Jenkins DM, Betley TA, Peters JC. J. Am. Chem. Soc 2002:11238. [PubMed: 12236716] (b) Dai X, Kapoor P, Warren TH. J. Am. Chem. Soc 2004;126:4798. [PubMed: 15080682] (c) Hu X, Meyer K. J. Am. Chem. Soc 2004;126:16322. [PubMed: 15600324] (d) Mehn MP, Brown SD, Jenkins DM, Peters JC, Que L. Inorg. Chem 2006;45:7417. [PubMed: 16933946]

12(a). Mayer JM, Rhile IJ, Larsen FB, Mader EA, Markle TF, DiPasquale AG. Photosynth. Res 2006;87:3. [PubMed: 16437185] (b) Roth JP, Lovell S, Mayer JM. J. Am. Chem. Soc 2000;122:5486. (c) Lebeau EL, Binstead RA, Meyer TJ. J. Am. Chem. Soc 2001;123:10535. [PubMed: 11673985] (d) Soper JD, Mayer JM. J. Am. Chem. Soc 2003;125:12217. [PubMed: 14519007]

13. Mindiola DJ, Hillhouse GL. J. Am. Chem. Soc 2001;123:4623. [PubMed: 11457258]

14. Alternate spin states were found to be within $12 \mathrm{kcal} / \mathrm{mol}$ of the lowest energy spin state. See SI for details.

15. Lucarini M, Pedrielli P, Pedulli GF, Cabiddu S, Fattuoni C. J. Org. Chem 1996;61:9259. 
16(a). Bordwell FG, Cheng J-P, Ji G-Z, Satish AV, Zhang X. J. Am. Chem. Soc 1991;113:9790. (b) Bordwell FG, Liu W-Z. J. Am. Chem. Soc 1996;118:10819. 


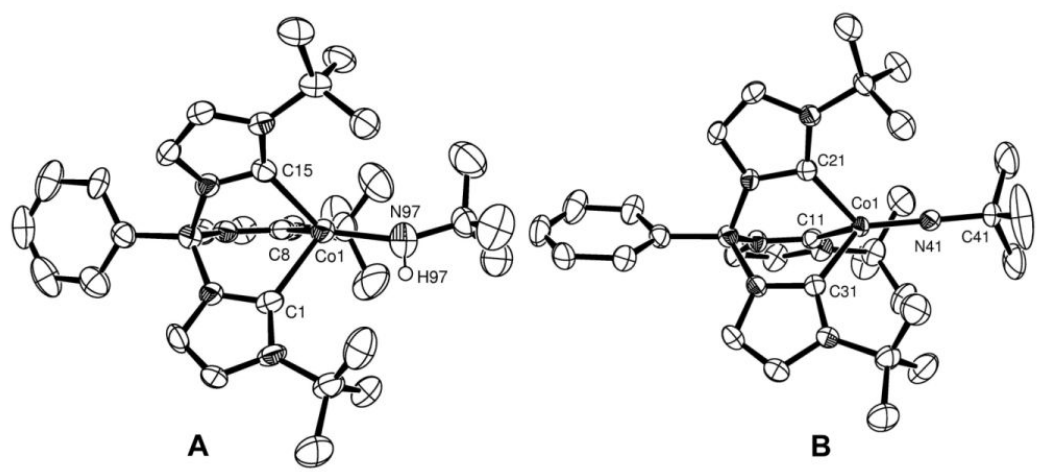

Figure 1.

(a) ORTEP diagram of one of the molecules in the asymmetric unit of $\mathrm{LCoNH}^{\mathrm{t}} \mathrm{Bu}$. Thermal ellipsoids shown at 50\% probability. Selected bond lengths and angles: $\mathrm{Co}(1)-\mathrm{N}(97) 1.886$ (7), $\mathrm{Co}(1)-\mathrm{C}(1) 2.128(7), \mathrm{Co}(1)-\mathrm{C}(8) 2.064(7), \mathrm{Co}(1)-\mathrm{C}(15) 2.099(6), \mathrm{Co}(1)-\mathrm{N}(97)-$ $\mathrm{C}(28)$ 153.5(6), $\mathrm{C}(1)-\mathrm{Co}(1)-\mathrm{C}(8)$ 91.6(2), C(1)-Co(1)-C(15) 89.9(2), $\mathrm{C}(8)-\mathrm{Co}(1)-\mathrm{C}$ (15) 93.4(2) (b) ORTEP diagram of $\mathrm{LCoN}^{\mathrm{t} B u}$. Thermal ellipsoids shown at 50\% probability. Selected bond lengths $(\AA)$ and angles $\left(^{\circ}\right)$ : $\mathrm{Co}(1)-\mathrm{N}(41) 1.660(3), \mathrm{Co}(1)-\mathrm{C}(11) 1.988(4)$, Co (1) $-\mathrm{C}(21)$ 1.949(4), $\mathrm{Co}(1)-\mathrm{C}(31)$ 1.952(4), $\mathrm{Co}(1)-\mathrm{N}(41)-\mathrm{C}(41)$ 179.7(3), $\mathrm{C}(11)-\mathrm{Co}(1)$ $-\mathrm{C}(21)$ 90.6(2), $\mathrm{C}(11)-\mathrm{Co}(1)-\mathrm{C}(31) 86.8(2), \mathrm{C}(21)-\mathrm{Co}(1)-\mathrm{C}(31) 87.7(2)$. 

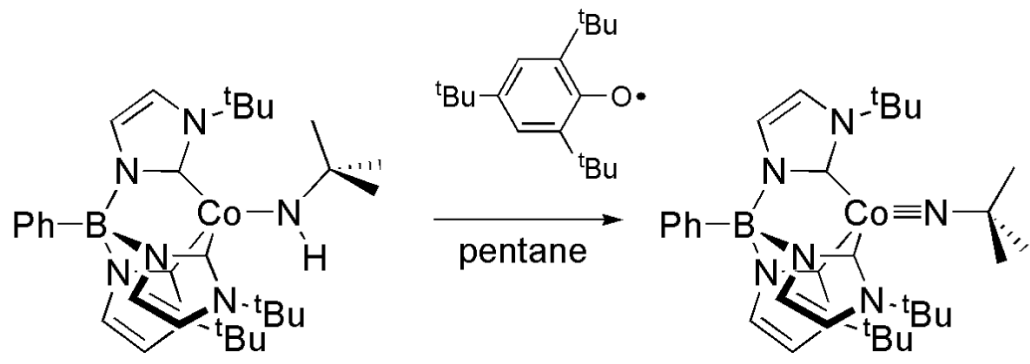

Scheme 1. 

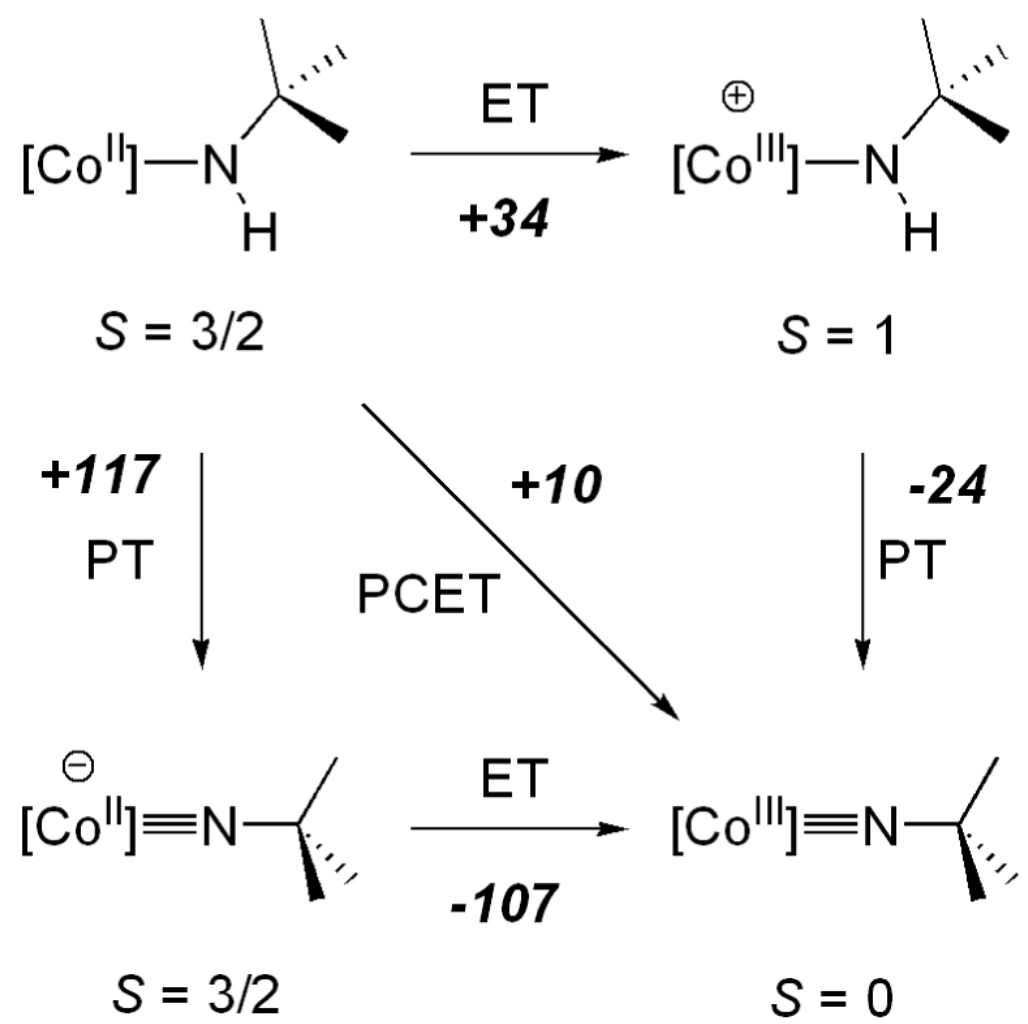

Scheme 2.

Calculated thermodynamic cycle in diethyl ether (B3LYP/6-31G*, PCM) showing relative free energies (kcal/mol). 